\title{
When to Buy and Sell the Shares of the Publicly Traded Rivals of a Firm Making an Initial Public Offering: A New Model
}

\author{
Miguel Ángel Carrasco-Mimbrera, Fernando Borrajo-Millán and María del Mar Alonso-Almeida*
}

\author{
Business Organization Department, Faculty of Economics and Business Administration, Autonomous \\ University of Madrid; Address: Calle Francisco Tomás y Valiente, 5. Ciudad Universitaria de Cantoblanco. \\ Madrid. Spain. CP: 28049.
}

\begin{abstract}
A review of the literature regarding the supply shock effects of a firm's initial public offering on its publicly traded rivals leads to a redefinition of the competitive and contagion effects. Owing to the persistence of the competitive effect over time and in different markets, it is identified as an anomaly. Therefore, we develop a 3D graphic tool capable of measuring systematically, from a continuous perspective, how information leaks into a stock market and how its effect on the returns of publicly traded companies spreads, in depth and length. The tool can be applied to any event study. In this study, it was used to visualize the short-term effects produced by a firm's initial public offering on its traded rivals in the Spanish stock market, using data over a 30-year period. A competitive effect, similar in size and extent to the ones detected by the state-of-the-art studies, was demonstrated. These results are comparable to the projections of the main asset pricing models. This demonstrates the similarity between the above stated competitive effect and the substitution effect related to the supply and demand theory regarding substitutive products. Based on this, a theory capable of explaining the competitive effect is proposed.
\end{abstract}

Keywords: Competitive Effect; Contagion Effect; Efficient Market Hypothesis; Event Study; Market Anomaly; Stock Markets; Supply Shock.

\section{INTRODUCTION}

The semi-strong version of Fama's (1970, 1991) efficient market hypothesis (EMH) states that a market is efficient when the prices reflect all the publicly available information. In line with many other studies, this event study uses this hypothesis to detail how and when the information is reflected in market returns and prices.

Those studies that focus on the way that information produced by a positive supply shock spreads along the market in the short term do not take into account the literature focused on the effects of the opposite supply shocks, and vice versa. In this study, both are reviewed and compared.

All the studies use a similar methodology. They contrast the statistical and economical significance of certain specific moments around an event. In this study, a tool is developed that is capable of analyzing systematically and continuously all the effects that a supply shock has on publicly traded shares for different time spans.

After reviewing the literature that focuses on the positive and negative supply shock effects among publicly traded companies, two main results stand out: one with the same direction

\footnotetext{
*Address correspondence to this author at Business Organization Department, Faculty of Economics and Business Administration, Autonomous University of Madrid; Address: Calle Francisco Tomás y Valiente, 5. Ciudad Universitaria de Cantoblanco. Madrid. Spain. CP: 28049.;

Tel: 0034 914976956; E-mail: miguelangel@ carrascomimbrera.com
}

as the supply shock, and the other with the opposite direction. If a competitive relationship is identified among the firms, the second situation prevails. If not, the first one reigns. A synthesis of previous studies unveils the nature of the second effect: over time, known but unexplained regular patterns can be forecast and used to obtain benefits. Therefore, this work classifies it as a market anomaly and describes its competitive effect.

This study analyzes the short-term effects of a firm's initial public offering (IPO) on its publicly traded rivals on the Spanish stock market (Mercado Continuo Español). A main negative effect is expected, opposite to the positive supply shock that induced it. The hypothesis of this study is that an IPO induces a negative effect over its rival's returns.

The literature explains the results from different perspectives. Some authors analyze the existing relationships between structural and financial variables and the encountered outcomes. Others state that the effects are the response of the transmission of private information to the stock market. Some see them as a reflex from the real economy. Last, but not least, a few use the projections of the main capital asset pricing models to justify them. This study follows this last investigation branch, depending on the supply and demand laws that underlie all asset pricing models (Lo, 2004). This point of view encourages the proposal of a theory that establishes a relationship between the competitive and substitution effects. The former relates to the supply shock effects on the publicly traded rivals and the latter relates to the laws of supply and demand, specifically with substitutive products. 
The rest of the paper is organized as follows: The rest of this section reviews the literature: It starts by relating the results of the studies focused on positive and negative supply shocks and redefining competitive and contagion effects. Then, counterexamples and their differences in methodology are examined. Later, the need of a tool capable of visually exposing the effects from a continuous perspective is presented. The review ends by enumerating the several points of view that the literature uses to explain the different results. Section 2 presents the methodology. Section 3 presents and analyzes the results. Section 4 discusses the significance of the results and proposes a theory that can explain the competitive effect anomaly. Section 5 summarizes the study, presents the conclusions, and proposes future lines of research.

\subsection{Competitive and Contagion Effects}

The literature identifies two main effects on a firm's publicly traded rivals, induced by a positive or a negative supply shock: a competitive effect, defined by an opposite reaction, and a contagion effect, characterized by a response in the same direction. In this paper, these main features will be used as the definition of the effects. Table $\mathbf{1}$ is an overview of the main papers and the effects discovered.

Table 1. Supply Shock Effects

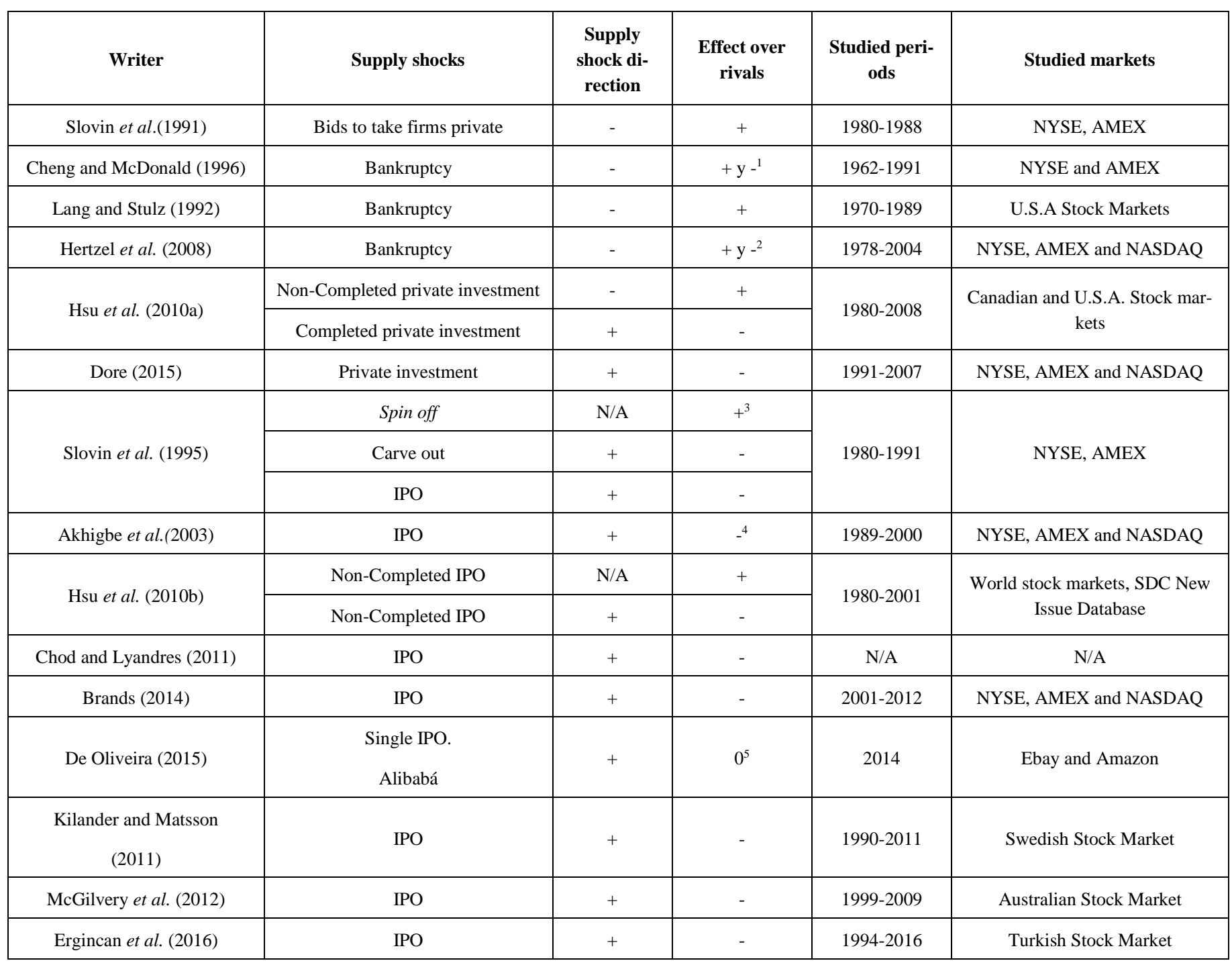

Source: Own elaboration

\footnotetext{
${ }^{1}$ Airline industry (positive) and railroad industry (negative).

${ }^{2}$ Competitive effect (positive) and contagion effect (negative)

${ }^{3}$ They come from pro rata stock dividends that distribute subsidiary ownership to the shareholders or the parent firm.

${ }^{4}$ Absence of economic significance.

${ }^{5}$ Absence of statistical significance effects.
} 
The literature started by analyzing negative shock effects, like the ones induced by bids to take firms private or by bankruptcies. Slovin et al. (1991) conducted the first study analyzing the effects on the shares of publicly traded rivals. They showed the impact of 128 bids to take firms on the NYSE and the AMEX stock market private on publicly traded competitors in the same industry. They noted a positive effect with a maximum value of around $17 \%$.

The first authors to talk about the competitive and the contagion effects were Lang and Stulz (1992). They studied the reaction of the rivals of 59 firms on U.S. stock markets that went bankrupt. They defined the contagion effect as "the wealth loss experienced by firms with cash flow characteristics similar of those of the bankrupt firm" and the competitive effect as "the wealth gain experienced by competitors." As stated in the first paragraph of this paper, the scope of these early stage definitions is now extended. Now they refer not only to bankruptcies but to any supply shock. Later on, this kind of research was extended to positive supply shocks like private investments and IPOs.

Slovin et al. (1995) compared the effects produced by the different ways a business or part thereof can change ownership. They analyzed the valuation changes experienced by the traded shares of the competitor firms within the same industry when an IPO is successful They studied IPOs related with demergers (firms created from another publicly traded one that are in charge of one or several business branches that were initially managed by the original firm). The research focused on carve-outs and spin-offs. In the former cases, at least, some of the new shares were sold to the public. In the latter cases, all of the new shares were distributed among the shareholders of the original firm. The returns of the publicly traded rivals experienced a statistically negative reaction to the carve-outs and a positive one to the spin-offs. They compared these results with the negative effect induced by traditional IPOs. This study showed that a positive supply shock (like a traditional IPO or a carve-out) triggers an opposite effect among the returns of the publicly traded competitors; meanwhile, a sole distribution of dividends (spinoff), although it creates a new firm, induces a positive one. Lastly, they did not find any statistically significant difference among the returns of the publicly traded rivals when a firm sells their assets to another in the same industry. Since there is no supply shock, an asset sell-off does not affect the competitors.

The latest research about the effects induced by an IPO on publicly traded rivals was done by Brands (2014). In his Master Thesis, studying the period 2001-2012, he found a statistically significant negative effect of 385 IPOs on U.S. stock markets (NYSE, AMEX, and NASDAQ) on competitors.

Recently, Dore (2015) linked the increase of equity (positive share supply shock) with rivals' negative returns. He showed that venture capital investment in small private firms provoked a negative effect on the returns of their publicly traded rivals. He found that increased venture capital investment has a large effect on incumbent profitability. Since the firms respond by reallocating their resources away from the threat- ened markets and by reducing the labor use, the effects have a short lifespan.

Although the majority of the research on the competitive effect has been done on U.S. stock markets, there is evidence of it in some other stock markets. Hsu et al. (2010a, 2010b) demonstrated its presence in Canada. Kilander and Matsson (2011), McGilvery et al. (2012), and Ergincan et al. (2016) showed its presence in the Swedish, Australian, and Turkish stock markets, respectively. This study extends the research to the Spanish stock market.

The result of all the above-mentioned studies are aligned with the ones obtained by Chod and Lyandres (2011). These authors, while proposing a theory about a firm's incentives to go public in the presence of product market competition, showed that an IPO has a negative effect on the value of the products sold by their rivals. This effect on the real economy could be transferred to the stock market.

A review of the literature that studies the effects of a positive or negative supply shock on the returns of publicly traded rivals shows that the main statistically and economically significant effect is opposite in direction to the original supply shock. In this paper, this characteristic is used to define the competitive effect. At the same time, the effect that has the same direction as the initial supply shock is called the contagion effect. The abovementioned studies show a known but inexplicable regular pattern in the rivals' returns over time when an offer shock takes place. The competitive effect is consistent through time and markets. There is still no consensus over its explanations. For these reasons, in this study the competitive effect is identified as an anomaly.

\subsection{Counterexamples and Methodology}

As stated in the previous section, the major studies since the 1960s show that the competitive effect prevails over the contagion effect regarding the returns of a firm's publicly traded rivals when a supply shock takes place. In this section, counterexamples, where no economical or statistical significance is found or where the contagion effect dominates, are presented and explained.

Some studies, based only on specific sectors, do not clearly show what the prevalent direction of the effect is. Cheng and McDonald (1996) analyzed the effect of bankruptcy on two U.S. industries, airlines and railroads. A bankruptcy announcement triggered statistically significant abnormal positive returns in the airline industry (the highest, $1.89 \%$, obtained the day before the bankruptcy) but statistically significant abnormal negative returns in the railroad industry (the highest,-0.89\%, obtained on the event day).

As stated in Table 2 and previously discussed by Hsu et al. (2010a, 2010b), researchers are yet to measure the length of the effects that a supply shock induces. However, to avoid overlapping effects, the majority of the studies analyze only isolated events, or at least they only include ones big enough to distinguish its effects from those of other events. Akhigbe et al. (2003) did not follow this approach. As stated by Hsu et al. (2010b), this could have caused the statistically significant small (0.02\%) outcomes obtained. Akhigbe et al. (2003) concluded that those small results, which are not economi- 
cally significant, can be explained by a mix of contagion (caused by the positive information given by the IPO) and competitive (caused by the competition that an IPO means) effects. To avoid analyzing overlapping effects, the present study focused only on the outcomes of IPOs separated by at least 464 trading days.

Hertzel et al. (2008) analyzed 250 firms that went bankrupt. Their results show that the contagion negative effect (with a maximum of around $-4 \%$ ) overrides the competitive positive one (with a maximum of around $0.13 \%$ ). This seems to contradict the major studies. This illusive divergence can be explained by the differences in methodology:

- The leading bankruptcy studies analyzed the effects on competitors the day when the event took place; meanwhile, Hertzel et al. (2008) focused their research on the day when the negative information flowed through the market.

- Hertzel et al. (2008) included in their research only those bankrupt firms that at least had a known identified customer or supplier. These authors conclude that the suppliers and customers suffer a negative contagion effect. This could have been transmitted through the value chain to the selected analyzed rivals.

De Oliveira (2015) studied the effects that the Alibaba IPO (which took place in 2014) had on its two main competitors, Amazon and eBay. The lack of statistical significance of the results of the biggest IPO in history could be ascribed to homoscedasticity and to the limited period that was analyzed.

\subsection{The Discrete and the Continuous}

As is shown in Table 2, the main studies analyzed effects over a specific period divided in four or five discrete subperiods from which they want to obtain more information.
Although the event studies showed how and when the information flows into the stock market, the subperiods were not analyzed from a continuous perspective. In this study, a tool is used and developed with which short time effects can be studied from a continuous point of view. The semi-strong EMH (Fama, 1970, 1991) states that all the available public information is reflected in the stock returns and prices. This should change with the increasing probability of a supply shock. This fact is highlighted by Hsu et al. (2010a, 2010b), who studied completed and uncompleted supply shocks.

Hsu et al. (2010b) studied the effects of two events related to IPOs on competitors. They used worldwide data. They analyzed the outcome of 134 completed IPOs and 37 uncompleted ones. Both had statistically and economically significant effects on their rivals. The completed ones induced a negative result, while the outcomes of the uncompleted ones were positive. The statistical significance of the effects of the completed IPOs lasted up to 20 days after the event and reached a maximum of $-0.82 \%$. The statistically significant outcome of the uncompleted IPOs extended over the studied period (10 days before until 20 days after the withdrawal), except for the 5 days before and after the IPO. It showed a maximum effect of $1.97 \%$.

In their other study, Hsu et al. (2010a) worked with U.S. and Canadian stock market data. They analyzed, within a period of 5 days before the event to 20 days after, the effects on rivals of two kinds of supply shock: First, they studied the effects of 13,087 firms that received private equity investment. They found that the returns and the operating ratios of the rivals decreased (the maximum was $1.4 \%$ ). Second, they researched the effects of 212 firms who had announced that private equity investment was withdrawn. They found that a private equity withdrawal induces an improvement of the returns and the operating ratios of the rivals. The maximum increase of the returns was $0.37 \%$.

Table 2. Methodology Review.

\begin{tabular}{|c|c|c|c|c|}
\hline Authors & Event Period & Classification & Results & $\begin{array}{c}\text { Isolated } \\
\text { events }\end{array}$ \\
\hline Slovin et al. (1991) & $(-15,-2),(-1,0)$ y $(1,15)$ & 4 digit SIC in CRSP & $\begin{array}{l}\text { Maximum value } \\
\text { around } 17 \%\end{array}$ & Yes $^{6}$ \\
\hline Cheng and McDonald (1996) & $\begin{array}{l}\text { Several periods of single and multiple days } \\
\text { since }(-20,0) \text { to }(0,20)\end{array}$ & Airlines and railroads & $\begin{array}{l}1.89 \% \text { airlines and (- } \\
0,89) \text { railroads }\end{array}$ & $\mathrm{Yes}^{7}$ \\
\hline Lang and Stulz (1992) & $(-1,0),(-5,5)$ & 4 digits SIC in COMPUSTAT & Around $1 \%$ & $\mathrm{Yes}^{8}$ \\
\hline Hertzel et al. (2008) & $(-2,2),(-1,0)$ and $(-5,5)$ & $\begin{array}{l}4 \text { digits SIC in COMPUSTAT } \\
\text { or in CRSP. }\end{array}$ & $(-4 \%)$ and $(0.13 \%)$ & Yes \\
\hline \multirow{2}{*}{ Hsu et al. (2010a) } & \multirow{2}{*}{$(-5,20)$} & \multirow{2}{*}{6 digits GICS } & Maximum of $(0.37 \%)$ & \multirow{2}{*}{ Yes $^{9}$} \\
\hline & & & Maximum of $(-1.4 \%)$ & \\
\hline Dore (2015) & N/A & 3 digits SIC COMPUSTAT & N/A & Yes $^{10}$ \\
\hline
\end{tabular}

\footnotetext{
${ }^{6}$ Conglomerates, utilities and financial firms are excluded.

${ }^{7}$ Only those firms with obligations higher than 120 million $\$$ are included in the sample.

${ }^{8}$ They make value-weighted portfolios.

${ }^{9}$ The transaction value $>10$ million $\$$. Do not take into account those events followed or precede by others bigger of the same type and within the same industry during a period of 6 months. The rivals must have been listed at least three years before the event.
} 


\begin{tabular}{|c|c|c|c|c|}
\hline Authors & Event Period & Classification & Results & $\begin{array}{c}\text { Isolated } \\
\text { events }\end{array}$ \\
\hline Slovin et al. (1995) & $(0,1),(-10,-1),(2,11)$ & 4 digits SIC & Around $1 \%$ & Yes $^{11}$ \\
\hline Akhigbe et al. (2003) & $(0,1),(2,10)$ & 4 digits SIC & $(-0.02 \%)$ & NO \\
\hline \multirow{2}{*}{ Hsu et al. (2010b) } & \multirow{2}{*}{$(-10,20),(-5,5)$} & \multirow{2}{*}{2 digits SIC } & $1,97 \%$ & \multirow{2}{*}{ Yes $^{12}$} \\
\hline & & & $-0,82 \%$ & \\
\hline Chod and Lyandres (2011) & N/A & N/A & N/A & N/A \\
\hline Brands (2014) & $(-10,10),(-5,5),(-1,1)$ & 4 digits SIC & Maximum of $(-0.42 \%)$ & Yes $^{13}$ \\
\hline De Oliveira (2015) & N/A & Ebay and Amazon & N/A & N/A \\
\hline Kilander and Matsson (2011) & Ten subperiods within the period $(-10,10)$ & 3 digits SIC & $(-4.5 \%)$ & Yes $^{14}$ \\
\hline McGilvery et al. (2012) & $\begin{array}{l}\text { Several periods of single and multiple days } \\
\qquad \text { since }(-2,9) \text { to }(-6,6)\end{array}$ & 6 digits GICS & $(-3 \%)$ & No \\
\hline Ergincan et al. (2016) & N/A & $\begin{array}{l}\text { Istanbul Stock Exchange indus- } \\
\text { trial sectors }\end{array}$ & N/A & Yes $^{15}$ \\
\hline
\end{tabular}

Source: Own elaboration

\subsection{Explaining the Results}

The literature tries to explain the results from four different perspectives.

Initially, financial and structural variables were used. Lang and Stulz (1992) were the first to relate contagion and competitive effects to industry leverage and degree of competition. They divided 59 bankrupt firms into two categories: companies belonging to industries with a high degree of leverage and competition and those in industries with the opposite characteristics. In the first sample they found a negative effect, at around $(-3.2 \%)$, on the rivals. In the second the competitor firms reacted positively, at around (2.2\%). Other authors continued this line of research, relating structural variables with the prevalence of one or the other effect. Cheng and McDonald (1996) stated that the different market structure characteristics of the U.S. airline and railroad industries are responsible for the different reactions of rivals to a bankruptcy. The positive effects on competitors obtained by Akhigbe et al. (2003) would have been provoked by IPOs that took place in highly regulated industries and in those sectors that have not had an IPO for a long time. The negative effects would have been related to relatively large IPOs that took place within very competitive, relatively risky, and better-performing industries and within the technology sector. These results partially agree with those of Kilander and Matsson (2011), who were not able to relate the leverage level with the competitive effect, but held that it is stronger in research intensive firms.
As previously shown, the studies do not stablish the same relationships within the different variables. The conclusions of Hsu et al. (2010a) partially challenged the preceding ones. They stated that publicly traded rivals with fewer financial constraints (less leveraged), who spend more on research and development (have more knowledge capital), and whose IPO had been underwritten (by a top investment bank or a venture capitalist) are less sensitive to the competitive effect. One year later, Hsu et al. (2010b) added to the previous variables the operating efficiency, the managerial incentives, and the performance difference among competitors as key factors of the degree of exposure to competitive effect. Brands (2014) did not succeed in relating the level of homogeneity in the industry or the absence of previous IPOs in the sector with the competitive effect.

The second branch of research was started by Slovin et al. $(1991,1995)$. They related the results to the leakage of private information in the stock market. To do so, they used several signaling models. Hertzel et al. (2008) saw results as a consequence of the leakage of information across the value chain. McGilvery et al. (2012), combining the previous points of view, used the way the information spreads through the market and the friction the diffusion produces to explain the relationship of the financial variables to the depth of the effects. They argued that those IPOs whose main aims are to reduce leverage and to invest in specific products are the ones who produce a higher negative effect on the rivals.

\footnotetext{
${ }^{10}$ The competitors must have been listed at least one year. Only firms that share codes 10 and 11 .

${ }^{11}$ They form part of Mergers \& Acquisitions' annual 'Largest Divestitures' and 'Top 100' transactions lists. Do not use closed-end funds, financial institutions and utilities. SIC codes of the parent and the subsidiary are checked to be different.

${ }^{12}$ IPOs are not preceded or followed by a larger IPO in the same two-digit SIC industry in the surrounding 6 years. The research focuses in high volume IPOs. The rivals must have been listed at least three years before the IPO.

${ }_{13}^{13}$ Financial firms and those IPOs with a deal value $<50$ million $\$$ are excluded.

${ }^{14}$ They use dummy variables to track how many years have passed since the last IPO in the industry.

${ }^{15}$ They work with the top 1000 industry firms in Turkey.
} 
The third branch related the results with the effects that the events produce in the real economy. Chod and Lyandres (2011) showed that a firm's IPO affects the value of their rivals' products negatively. Dore (2015) related a firm's increase in equity with the negative returns of its rivals. He argued that the effects are due to an increase in costs and not a decrease in revenues. Ergincan et al. (2016) stated that there is a high probability that the operating ratios, profits, and the prices of the shares of competitors are negatively affected when an IPO appears. This argument is based on interdependency and on the contagion channels within the rival firms. Recently, Elyasiani et al. (2015) researched the linkage among competitors, focusing on the financial and insurance sectors. They studied the relationship between the volatility and returns of United States, European, British, and Japanese companies. They argue that variables like size and leverage are the main transmission channels. Helwege and Zhang (2016), focusing on financial companies, analyzed the risk of bankruptcy among rivals. They found two main contagion channels: one related to the firm interlinkage and other related to the transmission of information.

Last but not least, the fourth point of view uses the two main asset pricing models to explain the results. This study used this approach. The arguments of Braun and Larrain (2009) deserve a closer look:

The models that assume that investors have a constant relative risk aversion (CRRA): There are no frictions restricting arbitrage. The demand is flat. It can be expressed by the following equation:

$\Delta \mathrm{E}\left(\mathrm{r}_{i}\right)=\gamma \omega_{I P O} \sigma_{i, I P O}$

The variation of the expected returns of asset " $i$ " is defined by the covariance of the returns between the IPO and the asset $\left(\sigma_{i, I P O}\right)$, the weight of the IPO in the market $\left(\omega_{I P O}\right)$, and the CRRA of the representative investor $(\gamma)$. A positive sign indicates that if the covariance between the IPO and the asset is positive $\left(\sigma_{i, I P O}\right)$ an increase of the IPO weight in the market $\left(\omega_{I P O}\right)$ will induce an increase in the expected returns of the asset "i", which at the same time will provoke a decrease in the price and a decrease in the returns. It will have a negative impact on rivals.

The models that assume that investors have a constant absolute risk aversion (CARA): These models take into consideration possible frictions that restrict the market's capacity to bear risks and limits the market's ability to adjust to different shocks. The demand has a downward slope. Behavioral finance uses these kinds of models. The following equation can represent them:

$\Delta \mathrm{P}_{i}=\gamma \mathrm{Q}_{I P O} \sigma_{i, I P O}$

The price variation of the asset " $\mathrm{i}$ " $\left(\Delta \mathrm{P}_{\mathrm{i}}\right)$ is defined by the covariance of the prices between the IPO and the asset $\left(\sigma_{i, I P O}\right)$, the CARA of the representative investor $(\gamma)$, and by the IPO size $\left(\mathrm{Q}_{I P O}\right)$. The negative sign indicates that if the covariance between the IPO and the asset is positive, $\left(\sigma_{i, I P O}\right)$ an increase in the IPO shares $\left(\mathrm{Q}_{I P O}\right)$ will induce a fall in the price of the asset " $i$." At the same time, it will provoke a decrease in the returns and an increase in the expected returns. It will have a negative impact on rivals.

This study compared the forecasts of both models with the empirical results.

\section{MATERIALS AND METHODOLOGY}

\subsection{Data}

The data used were the daily closing prices of the companies listed on the Spanish stock market from February 1986 to July 2016. The data is available on the BME trading platform (the company of Spanish financial markets). The database contains 172 companies.

The literature groups publicly traded companies in order to analyze the effects of a supply shock on rivals. The lack of consensus among the different studies in making such a classification is shown in Table $\mathbf{2}$. This study analyzed the Spanish stock market, which is shallow and narrow. These characteristics make its official classification a good sorting system that is able to reflect the relationship between the traded firms. The different businesses are divided in sectors and subsectors. Using such a classification, rivals are firms in the same subsector.

This study analyzed the effects that an IPO has on the returns of the traded shares in the same IPO subsector. Initially, the first trading day was identified as the IPO day. Afterwards, public and media sources were used to verify it.

Only the effects of IPOs what were isolated in time, within a subsector, were studied. This avoids overlapping effects and distortions that could be induced by the estimation period used in the methodology.

Different time periods between IPOs in the same subsector were considered: $300,375,435,443,484,550,730,800$, and 1,050 trading days. Isolation lengths shorter than 358 trading days were discarded because the model uses an estimation period of 254 trading days plus a temporary jump of 43 trading days and an event period of 61 trading days. Therefore these events, despite producing a large observation sample, did not produce statistically significant data with the used methodology. Isolation lengths longer than 475 trading days produced a small sample of observations, which does not allow us to extend the results to the whole Spanish stock market.

Table 3. Events and Analyzed Rivals.

\begin{tabular}{|c|c|c|c|c|c|}
\hline \multicolumn{2}{|c|}{ I.P.O. } & \multicolumn{4}{|c|}{ IPO's and affected companies analyzed } \\
\hline Name & Ticker & Date & Sector & Subsector & Ticker affected companies \\
\hline Ferrovial, S.A. & FER & $05 / 05 / 1999$ & MB & MBC & URA, SYV, SCYR, OHL, FCC, CPL, CMC, ANA, ACS. \\
\hline
\end{tabular}




\begin{tabular}{|c|c|c|c|c|c|}
\hline \multicolumn{2}{|l|}{ I.P.O. } & \multicolumn{4}{|c|}{ IPO's and affected companies analyzed } \\
\hline Name & Ticker & Date & Sector & Subsector & Ticker affected companies \\
\hline Grupo Empresarial San José, S.A. & GSJ & 20/07/2009 & MB & $\mathrm{MBC}$ & $\begin{array}{c}\text { URA, SYV, SCYR, OHL, ITI, FER, FCC, CPL, CMC, } \\
\text { CLEO, CIN, ANA, ACS. }\end{array}$ \\
\hline Azkoyen, S.A. & AZK & 01/08/1988 & MB & $\mathrm{MBF}$ & ZOT, TUD, CAF. \\
\hline Gamesa Corporación Tecnológica & GAM & $31 / 10 / 2000$ & MB & $\mathrm{MBF}$ & ZOD, TUD, NEA, MLX, CAF, AZK \\
\hline Talgo, S.A. & TLGO & 07/05/2015 & MB & $\mathrm{MBF}$ & ZOD, NEA, GAM, ENO, CAF, AZK \\
\hline Abengoa, S.A. & $\mathrm{ABG}$ & 09/12/1996 & MB & MBI & MDF \\
\hline Befesa Medio Ambiente, S.A. & BMA & 01/07/1998 & MB & MBI & MDF, ABG. \\
\hline Fluidra, S.A. & FDR & $31 / 10 / 2007$ & MB & MBI & TRE, MDF, INY, GALQ, BMA, ABG. \\
\hline Aperam, S.A. & APAM & $04 / 02 / 2011$ & MB & MBM & TUB, TRG, MTS, LGT, CIE, ACX. \\
\hline Enagas, S.A. & ENG & $26 / 06 / 2002$ & $\mathrm{PE}$ & PEEG & UNF, REE, GAS, ELE. \\
\hline Red Electrica Corporación, S.A. & REE & 07/07/1999 & $\mathrm{PE}$ & PEEG & UNF, GAS, ELE. \\
\hline Enel Green Power, S.P.A. & EGPW & $04 / 11 / 2010$ & $\mathrm{PE}$ & PEEN & SLR, IBR, IBE, FRS \\
\hline Repsol, S.A. & REP & $11 / 05 / 1989$ & $\mathrm{PE}$ & PEP & CEP \\
\hline Saeta Yield, S.A & SAY & $16 / 02 / 2015$ & $\mathrm{PE}$ & PEEN & SLR, IBE, FRS, EGPW. \\
\hline Campofrio Alimentación S.A. & CFG & 04/08/1988 & $\mathrm{BC}$ & $\mathrm{BCAB}$ & VIS, AGS. \\
\hline Industria de Diseño Textil, S.A. & ITX & $23 / 05 / 2001$ & $\mathrm{BC}$ & BCTV & TVX, SNC, DGI, ADZ \\
\hline Oryzon Genomics & ORY & $14 / 12 / 2015$ & $\mathrm{BC}$ & BCFB & ROVI, RJF, PRM, PHM, GRF, FAE, BIO, BAY, ALM \\
\hline Europistas, S.A. & EUR & $19 / 09 / 1988$ & SC & SCAA & ABE. \\
\hline DIA Supermercados, S.A & DIA & 05/07/2011 & SC & SCC & SPS \\
\hline Clínica Baviera, S.A. & CBAV & 03/04/2007 & SC & SCOS & PSG, FUN, DERM \\
\hline Dermoestética, S.A. & DERM & $13 / 07 / 2005$ & SC & SCOS & PSG, FUN. \\
\hline Funespaña, S. A. & FUN & $11 / 12 / 1998$ & SC & SCOS & PSG \\
\hline Codere, S.A. & $\mathrm{CDR}$ & $19 / 10 / 2007$ & SC & SCOT & NHH, MEL. \\
\hline Melia Hoteles Internacional, S.A. & MEL & 02/07/1996 & SC & SCOT & NHH. \\
\hline Edreams, S.A. & EDR & 08/04/2014 & SC & SCOT & NHH, MEL, CDR \\
\hline Parques Reunidos, S.A. & $\mathrm{PQR}$ & $29 / 04 / 2016$ & SC & SCOT & NHH, MEL, CDR, EDR \\
\hline International Airlines Group & IAG & 03/04/2001 & SC & SCTD & $\mathrm{ADV}$ \\
\hline Vueling Airlines S. A. & VLG & $01 / 12 / 2006$ & SC & SCTD & IAG (Iberia), ADV. \\
\hline Banco Sabadell, S.A. & $\mathrm{SAB}$ & $18 / 04 / 2001$ & SF & SFBC & XBFR,SAN, POP, PAS, GUI, BTO, BKT, BBVA, AND. \\
\hline BANKIA, S.A. & BKIA & $20 / 07 / 2011$ & SF & SFBC & SAN, SAB, POP, CAM, CABK, BKT, BBV \\
\hline Dinamia, S. A. $(\mathrm{N}+1)$ & DIN & $15 / 12 / 1997$ & SF & $\mathrm{SFCH}$ & ALB \\
\hline Hispania activos inmobiliarios, S.A. & HIS & $14 / 03 / 2014$ & $\mathrm{SF}$ & SFI & UBS, TST, STG, RLIA, QBT, MTB, ISUR, COL \\
\hline Renta 4 Banco, S.A. & $\mathrm{R} 4$ & $14 / 11 / 2007$ & SF & SFIN & BME. \\
\hline Amadeus IT Holding & AMS & $29 / 04 / 2010$ & TT & TTES & TEC, IDR, AMP \\
\hline Jazztel, P.L.C. & $\mathrm{JAZ}$ & $18 / 12 / 2000$ & TT & TTTO & TEF, EZE \\
\hline
\end{tabular}

Source: Own elaboration. 
Therefore, this study analyzed the effects of an IPO within its subsector, measuring only the effects of those IPOs more than 464 trading days apart. This criterion produced 35 events (IPOs) and 135 incumbents whose returns were analyzed. The events are almost evenly distributed along the time sample: Four took place before 1990, 7 during that decade, 13 during the first ten years of the 21 st century and 11 afterwards. Table $\mathbf{3}$ shows the events classified by subsectors.

The expected stock returns of the companies are calculated through the least squares method and the market model. To do so, the firms' daily stock returns during 254 trading days with a gap of 43 trading days were used. The last date considered is the 43rd day before the IPO. An estimation period of 255 trading days is employed.

Thereafter a variable time period was analyzed. The event period includes from 1 to 61 trading days. To do so, a multiperiod is built by splitting the studied period into all the possible sub-periods around the IPO. The cumulative average abnormal returns (CAARs) are represented in a threedimensional graph. The fluctuating graph shows the time intervals when the publicly traded rival firms were most or least affected by the event.

The market return is represented by the returns of the index IBEX35, or by the IGBM ones, in those cases where the former was not already developed.

\subsection{Indicators}

\subsubsection{Covariance}

The covariance shows the relationship between the incumbents and the IPO firm. It is calculated, for prices and returns, during each of the event periods (the first 31 trading days of every IPO).

Being:

$$
\begin{aligned}
& \operatorname{Cov}_{P_{t}}\left(P_{X}, P_{Y}\right)=\sum_{T_{20}}^{T_{2}}\left(P_{X}-\overline{P_{X}}\right) *\left(P_{Y}-\overline{\left.P_{Y}\right)}\right. \\
& \operatorname{Cov}_{P_{t}}\left(R_{X}, R_{Y}\right)=\sum_{T_{2,0+1}}^{T_{2}}\left(R_{X}-\overline{R_{X}}\right) *\left(R_{Y}-\overline{R_{Y}}\right)
\end{aligned}
$$

\subsubsection{Indicators Subject to Statistical Tests}

The Markowitz (1959) model is used to estimate the rivals' returns. $R_{i t}=\alpha_{i}+\beta_{i} R_{m t}+\varepsilon_{i t} R_{i t}$ are the stock returns of the rival company. $\mathrm{R}_{\mathrm{mt}}$, the returns of the market portfolio (the IBEX35 returns or the IGBM when the former was not already developed). $\alpha_{i}$ y $\beta_{i}$ are the estimation parameters and $\varepsilon_{\mathrm{it}}$ is the estimation error.

The parameters $\hat{\alpha}_{\mathrm{i}}, \hat{\beta}_{\mathrm{i}}$, are estimated over 254 trading days. They start 73 trading days before the event (the IPO). Altogether 43 of them come from the time jump and 30 correspond to the beginning of the event period. The event period consists of 61 trading days: The IPO day, 30 days before and 30 days after the event.
Abnormal returns: The expected returns are calculated with the expression $\widehat{R}_{i t}^{*}=\widehat{\alpha}_{i}+\widehat{\beta}_{i} R_{m t}{ }^{*} 16$. The difference between the actual stock returns and the expected returns are the abnormal returns: $A R_{t}^{*}=\mathrm{R}_{\mathrm{it}}{ }^{*}-\widehat{\mathrm{R}}_{\mathrm{it}}^{*}$.

Standardized abnormal returns: To avoid the volatility caused by the event, Patell $(1976,1979)$ proposed to standardize the abnormal returns. Then they are used to perform statistical tests. Patell uses the following formulae:

$S \varepsilon_{\mathrm{i}}^{*}=\frac{\hat{\varepsilon}_{\mathrm{i}}^{*}}{\sqrt{\hat{\sigma}_{\varepsilon^{*} \mathrm{i}^{*}}^{2}(1+d)}} \approx T_{L_{1}-2}$

The parameter $\mathrm{d}$ is defined by:

$d=\frac{1}{L_{1}}+\frac{R_{m L_{m}}-R_{m}}{\sum_{T_{0}}^{T_{11}} R_{m}-R_{m}}$

$R_{m}$ is the average market return during the estimation period. $L_{1}$ is the length of the estimation period. It corresponds to the number of observations during that period. $T_{0}$ represents the beginning of the estimation period, and $T_{1,1}$ its end. $\vec{\sigma}_{\varepsilon^{2}} i$ is the same estimator used for tests that are based on the statistical properties of abnormal returns.

Average abnormal returns: The average of the abnormal returns of each company, for each event period. For N companies:

$A A R_{t}=\frac{1}{N} \sum_{i=1}^{N} \hat{\varepsilon}_{i}^{*}$

The AARs are represented in a plane Cartesian coordinate system. The size, in percentage, positive or negative, is represented in the ordinate axis. The abscissa axis is a timeline of 61 trading days that is built based on the event period.

Standardized Average Abnormal Returns: The average of the standardized abnormal returns of each company, for each of the event periods. For $\mathrm{N}$ companies:

$S A A R=\frac{1}{N} \sum_{i=1}^{N} S \varepsilon_{\mathrm{i}}^{*}$

Cumulative Average Abnormal Returns: They are calculated by adding the AARs returns over time.

$\operatorname{CAAR}\left(t^{*}{ }_{1}, t^{*}{ }_{2}\right)=\frac{1}{N} \sum_{i=1}^{N} \sum_{t_{1}}^{t_{2}} \varepsilon_{\mathrm{it}}$ *

Standardized Cumulative Average Abnormal Returns: They are calculated by adding the SAARs over time.

$S C A A R_{i}\left(t^{*}{ }_{1}, t^{*}{ }_{2}\right)=\frac{1}{N} \sum_{i=1}^{N} \sum_{t_{1}}^{t_{2}} S \varepsilon_{\mathrm{i}}^{*}$

The time interval $\left(t^{*}{ }_{1}, t^{*}\right)$ has a variable length. The goal of the analysis of the CAARs and of the standardized ones is to verify the existence of a distortion and its time persistence. To observe the intensity of these features during the different periods, the length of the time interval $\left(t^{*}{ }_{1}, t^{*}\right)$ is modified. During the analysis, the time interval $\left(t^{*}{ }_{1}, t^{*}\right)$ is changed,

${ }^{16}$ The symbol * refers to the event period, while its absence refers to the estimation period. 
following all the possible combinations of the vector $(-29$, 30), which ranges from 29 days before the event until 30 days after it, including the event date. The CAARs and SCAARs are represented in a 3D coordinate graph. The size of the effect (positive or negative) is shown along the vertical axis. Two timelines are represented in the horizontal plane. Each of the points on the horizontal plane represents one of the sub-periods into which the event period has been divided. There are 1,860 sub-periods. Downwards is the pos- itive direction of the vertical axis at the CAARs and in the second statistical indicator, meanwhile in the first it is upwards. Only those points with a high probability to discard the initial null hypothesis are represented.

\subsubsection{Statistical Estimators}

The following indicators, showed in Table $\mathbf{4}$, are used to measure the statistical significance of the effects and to verify the hypothesis.

Table 4. Test Performed on the Joint Abnormal Returns. AAR and CAAR.

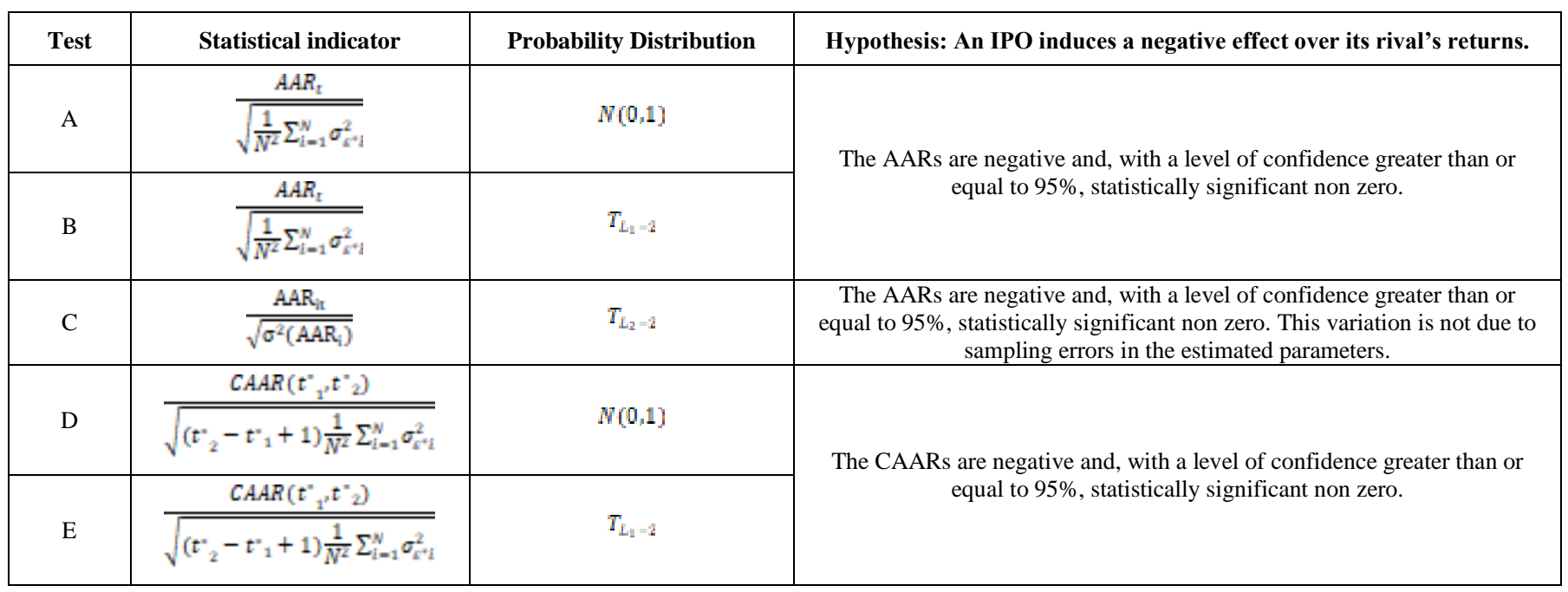

Source: Own elaboration

Table 5. Tests performed on the Joint Standardized Average Abnormal Returns. SAAR and SCAAR.

\begin{tabular}{|c|c|c|c|}
\hline Test & Statistical indicator & Probability distribution & $\begin{array}{c}\text { Hypothesis: An IPO induces a negative effect over its rival's } \\
\text { returns }\end{array}$ \\
\hline A.P & $\frac{s \sqrt[\varepsilon_{1}]{ }}{\sqrt{\frac{1}{N^{2}} * \Sigma_{1}^{*} \frac{L_{1}-2}{L_{1}-4}}}$ & $N(0,1)$ & \multirow{2}{*}{$\begin{array}{l}\text { The SAARs are negative, with a level of confidence greater than } \\
\text { or equal to } 95 \% \text {, statistically significant non-zero. }\end{array}$} \\
\hline B.P & $\frac{S \Sigma_{1}}{\sqrt{\frac{1}{N^{2}} * \Sigma_{1}^{*} \frac{L_{1}-2}{L_{1}-4}}}$ & $T_{L_{2}=1}$ & \\
\hline D.P & 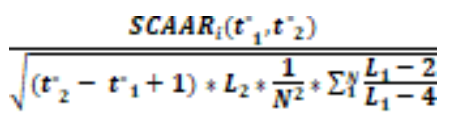 & $N(0,1)$ & \multirow{2}{*}{$\begin{array}{l}\text { The SCAARs are negative, with a level of confidence greater than } \\
\text { or equal to } 95 \% \text {, statistically significant non-zero. }\end{array}$} \\
\hline E.P & 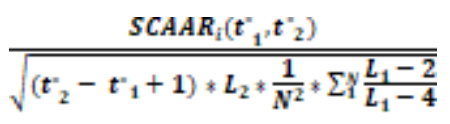 & $T_{\mathbb{L}_{\mathbb{L}}=\mathrm{I}}$ & \\
\hline
\end{tabular}

Source: Own elaboration.

Table 6. Positive $C_{o v P t}$ and $C_{o v R t}$. Same Subsector.

\begin{tabular}{|c|c|c|c|c|c|c|c|}
\hline Covariance (IPO, related company) & $\mathrm{N}^{0}$ observations & Positives & $>0$ y $<0,25$ & $>0,25$ & $>0,5$ & $>0,75$ & $>1$ \\
\hline \multirow{2}{*}{ Covariance of Price } & 135 & 76 & 68 & 8 & 8 & 4 & 3 \\
\hline & $\%$ over the total observations & $56,30 \%$ & $50,37 \%$ & $5,93 \%$ & $5,93 \%$ & $2,96 \%$ & $2,22 \%$ \\
\hline \multirow{2}{*}{ Covariance of returns } & 135 & 90 & 90 & 0 & 0 & 0 & 0 \\
\hline & $\%$ over the total observations & $66,67 \%$ & $66,67 \%$ & $0,00 \%$ & $0,00 \%$ & $0,00 \%$ & $0,00 \%$ \\
\hline
\end{tabular}


Source: Own elaboration

Table 7. Negative $C_{o v P t}$ and $C_{o v R t}$. Same Subsector.

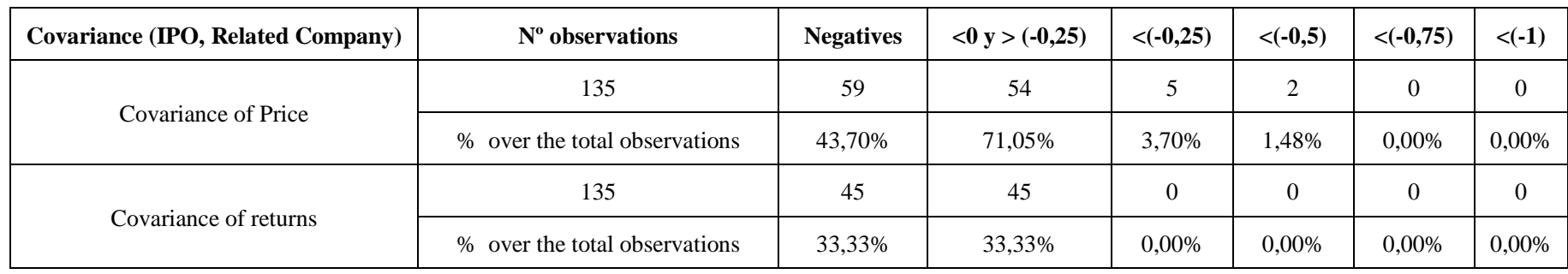

Source: Own elaboration

The Patell test $(1976,1979)$ was designed to avoid eventinduced volatility. It is used to jointly test the AAR and the CAAR. To do so the above indicators are standardized, being the SAAR and the SCAAR. Since these last indicators cannot be economically interpreted, where those are statistically significant the AAR and the CAAR are shown. Table 5 details the tests performed and their meaning in case of being significant.

\section{RESULTS}

\subsection{Number and Percentage of the Positive and Negative} $\operatorname{Cov}_{\mathrm{Pt}} \mathrm{Cov}_{\mathrm{R} t}$

The number and percentage of the positive and negative $\operatorname{Cov}_{P t} \operatorname{Cov}_{R t}$ are shown in Table 6 and Table 7. Most observations are positive. The absolute value of most positive and negative observations, for prices and returns, is between 0 and 0.5 .

\subsection{Average Abnormal Returns}

The firms' AARs of the subsector where the IPO took place are represented in Fig. (1).

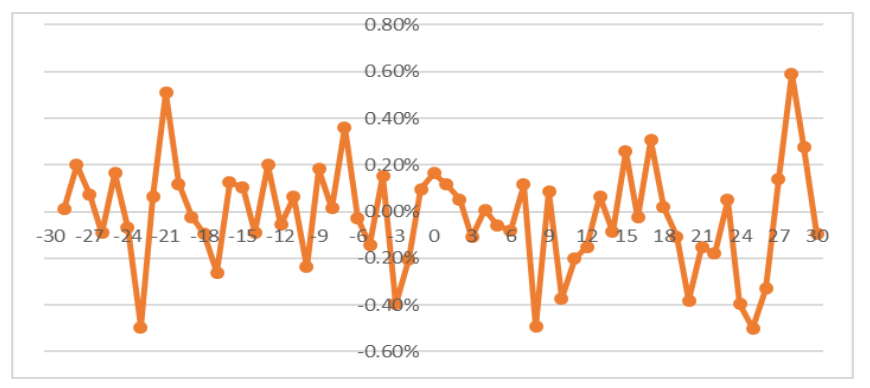

Fig. (1). Same Subsector AAR.

Positive and negative AARs can be seen. The negatives are more prevalent and outweigh the positives. The days that closely surround the event show slightly positive AARs. However, the days adjacent to those depict strongly negative AARs. The AARs vary during the event and on the surrounding trading days. This could have been induced by the IPO.

\subsection{Cumulative Average Abnormal Returns}

CAARs are represented in a three-dimensional graph in Fig. (2). The vertical axis is oriented with the negative values on top. The horizontal plane represents each of the sub-periods into which the event is divided. The CAARs fluctuate. They are mainly negative, which suggest a possible competitive effect. Its maximum (the greatest positive effect) is $1.01 \%$ and is observed in the vector [27, 29] which encompass the period from the 27 th trading day after the event until the 29 th, both included. It's minimum (the greatest negative effect) is $-2.91 \%$ and it is observed in the vector $[-6,26]$, which runs from the 6th trading day before the event until the 26th day afterwards, both included.

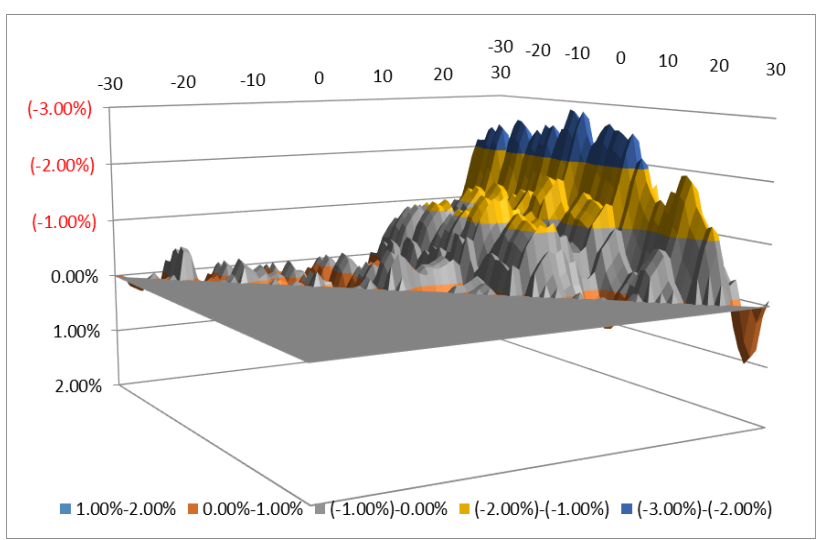

Fig. (2). CAAR. Same Subsector.

Source: Own elaboration

\subsection{Results of the Tests}

\subsubsection{Tests Performed on the Average Abnormal Returns and The Cumulative Average Abnormal Returns}

Tests A, B, and C are performed on the AARs and Tests D and $\mathrm{E}$ on the CAARs. The D tests are represented in a threedimensional graph, in which the vertical axis positive direction is oriented downwards. Test $\mathrm{E}$ is represented in a similar graph but with the positive direction of the vertical axis going up. It is represented in this way for a better visualization of statistically significant positive and negative CAARs.

Appendix A presents the non-graphed results for the three data panels of the $\mathrm{E}$ tests. The statistically significant CAARs are shown in black. The statistically significant negative CAARs are shown in red. Non-statistically significant CAARs are not shown.

Figure (3) represents the AARs of the companies traded and listed in the same subsector as the IPO and the conclusive results of tests $\mathrm{A}, \mathrm{B}$, and $\mathrm{C}$. 


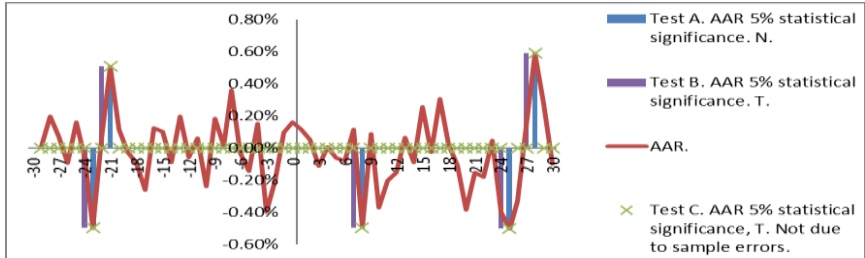

Fig. (3). Test A, B, and C. AARs. Same Subsector Source: Own elaboration

The statistically significant AARs are positive and negative, and do not occur near the day of the event. The results of the CAARs subjected to tests D and E appear in Fig. (4 and 5).

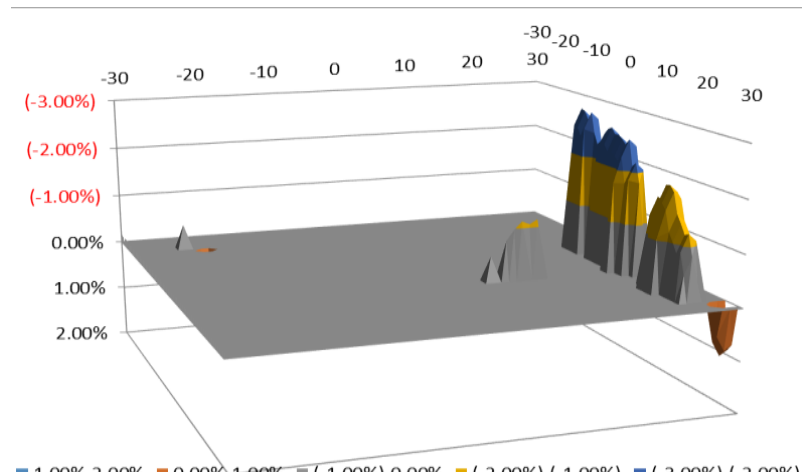

Fig. (4). Test D. CAAR $5 \%$ Statistical Significance with a Probability Distribution N $(0,1)$. Same Subsector.

Source: Own elaboration

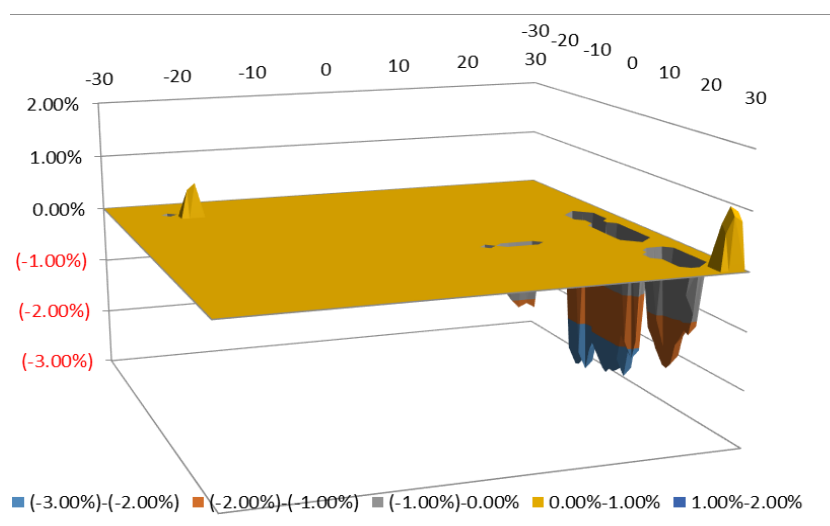

Fig. (5). Test E. CAAR $5 \%$ Statistical Significance with a Probability Distribution T. Same Subsector.

Source: Own elaboration

The statistically significant CAARs of both panels are mainly negative. The two tests reach a maximum of $1.01 \%$ and a minimum of $-2.91 \%$, placed respectively in vectors $[27,29]$ and $[-6,26]$.

\subsubsection{Tests Performed on the Standardized Average Ab- normal Returns and the Standardized Cumulative Average Abnormal Returns}

The A.P and B.P tests are used to analyze the SAARs. The D.P. and E.P. tests are used to study the SCAARs.

Since the SAARs and the SCAARs have no economic meaning, the statistically significant results of the tests done on those indicators are represented by the corresponding AARs and CAARs. The D.P tests are represented in a three- dimensional graph in which the vertical axis has the positive direction oriented downwards. The E.P test is represented in a similar graph but with the positive direction of the vertical axis facing upwards. This makes for an easier depiction of the statistically significant positive and negative CAARs. The results of the D.P and E.P tests are quite similar.

The tests based on Patell (A.P, B.P, D.P, and E.P) support the results of the test based on the statistical properties of the indicators (A, B, C, D, and E). The Patell tests are more robust with respect to possible volatility changes induced by the event. They avoid rejecting the null hypothesis excessively when the volatility has been induced by the same event.

Appendix B presents the results of the E.P test without 3D plotting. The CAARs which correspond to statistically significant SCAARs are depicted (the positive CAARs in black and the negative ones in red), while the CAARs related to the statistically non-significant SCAARs are represented by a white space. The SAAR and SCAAR tests of the firms' returns, placed in the same subsector where the IPO appears, are shown below. Tests A.P, B.P, D.P, and E.P are shown in Fig. (6), Fig. (7), and Fig. (8).

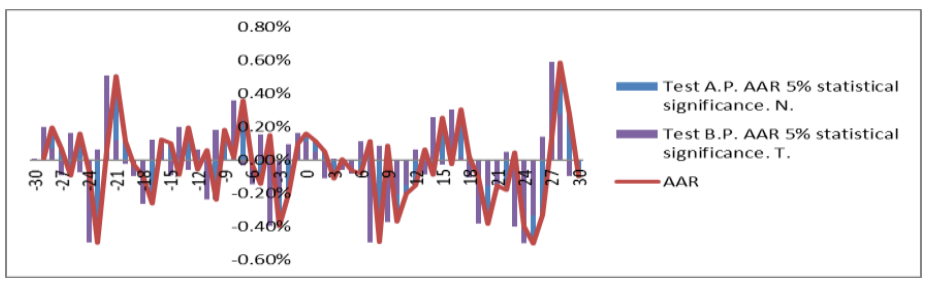

Fig. (6). Test A.P and B.P. SAARs. Same Subsector Source: Own elaboration

Almost all SAARs are statistically significant according to tests A.P and B.P. There are positive and negative AARs related with the statistically significant SAARs. The negative ones are deeper. CAARs which correspond to the statistically significant SCAARs produced by the D.P and E.P tests are shown in Fig. (7) and Fig. (8), respectively.

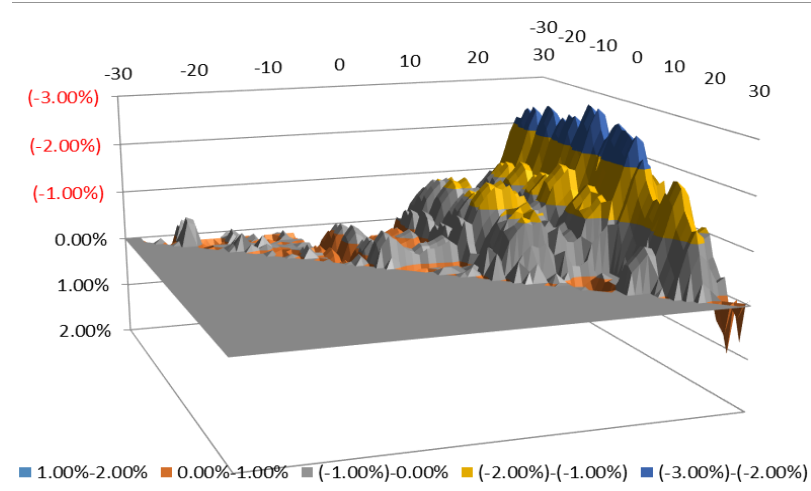

Fig. (7). D.P. Test. CAAR of the $5 \%$ Statistical Significance SCAAR with a Probability Distribution N $(0,1)$. Same Subsector Source: Own elaboration

The CAARs which correspond to the statistically significant SCAARs are mainly negative in both tests. The CAARs in both tests reach a maximum of $1.01 \%$ and a minimum of $2.91 \%$. They are placed respectively in vectors $[27,29]$ and $[-6,26]$. 


\subsection{Analysis of Results}

\subsubsection{Analysis of Positive and Negative $\operatorname{Cov}_{P t}$ and $\operatorname{Cov}_{R t}$}

The covariance between the IPO and each incumbent were calculated. Since the relationship between the data panel firms may change through time, the prices and returns covariance were calculated during the 30 trading days after each of the events. Since both indicators are close to zero, a small effect is expected.

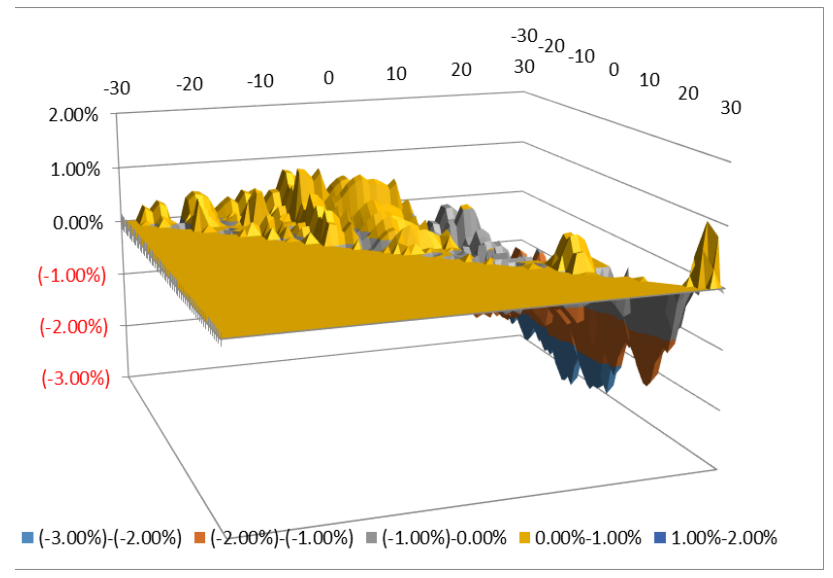

Fig. (8). E.P. Test. CAAR of the $5 \%$ Statistical Significance SCAAR with a Probability Distribution T. Same Subsector Source: Own elaboration

The results of these indicators were introduced in different asset pricing models. Models claiming that the investors have a CRRA forecast an increase in the expected returns, thus a decrease in the asset prices, if the covariance of returns between the IPO and the incumbent firm is positive. Behavioral finance models, which assume an investor's CARA, foresee a decrease in the asset prices if the prices covariance between the IPO and the incumbent is positive ${ }^{17}$.

\subsubsection{Analysis of the Results of Tests A, B, C, D, and E}

The AARs are analyzed with tests A, B, and C. Tests A and $\mathrm{B}$ indicate, with a level of confidence greater than or equal to $95 \%$, that the AARs are statistically significant and non-zero. Test $\mathrm{A}$ is distributed according to an $\mathrm{N}(0,1)$ and test $\mathrm{B}$ with a T-Student. Their sign indicates whether the effect on related companies has been positive or negative. Test $\mathrm{C}$ indicates, with a level of confidence greater than or equal to $95 \%$, that non-zero and statistically significant AARs are due to future distortions, and not because of sample errors in the estimated parameters.

Tests $\mathrm{A}, \mathrm{B}$, and $\mathrm{C}$ are only statistically significant in five AARs, two before and three after the IPO. The positive ones are on the 21 st trading day before the event and on the 28 th after. They have a value of $0.5 \%$ and $0.6 \%$, respectively. The negative ones are on the 23rd trading day before the event, and the 8 th and the 25 th after it. They have a value of $0.49 \%,-0.49 \%$, and $-0.5 \%$ respectively.

The CAARs are tested with tests D and E. Both indicate that the CAARs are, with a confidence level equal to or greater

\footnotetext{
${ }^{17}$ See Brawn and Larrain (2009).
}

than $95 \%$, statistically significant other than zero. The signs show whether the effect on the related companies has been positive or negative. For a better visualization of the CAARs, the results of $\mathrm{D}$ and $\mathrm{E}$ tests are represented in separate $3 \mathrm{D}$ graphs. The vertical axis of test $\mathrm{D}$ is facing down, while the one in test $\mathrm{E}$ is facing up.

Statistically significant CAARs in tests D and E reach their maximum and minimum in the same points and with the same values than the already analyzed CAARs. The maximum is $1.01 \%$, reached in the vector $[27,29]$. The minimum is $-2.91 \%$, reached in the vector $[-6,26]$.

The results of tests $\mathrm{A}, \mathrm{B}, \mathrm{C}, \mathrm{D}$, and $\mathrm{E}$ show that the analyzed rivals have been affected by the event. The main effect is negative; therefore it indicates a competitive effect.

The statistically significant CAARs are clustered within the period that starts 7 trading days before the event and ends 27 trading days after it. It seems that the negative effect only appears in that time interval. Concentrated at the end of the period appears an opposite effect, positive and of lesser intensity.

Fig. (4) and Fig. (5) show that the effect rises in saw-tooth waves. The wave peaks correspond to the trading days where maximums and minimums were obtained in tests $\mathrm{A}, \mathrm{B}$, and C.

\subsubsection{Analysis of the Results of Tests A.P, B.P, D.P, and E.P}

The SAARs were subjected to tests A.P and B.P. Those tests indicate, with a level of confidence greater than or equal to $95 \%$, that SAARs are statistically significant and non-zero. The A.P test is distributed according to an $\mathrm{N}(0,1)$ and the B.P test according to a T-Student. The SAARs cannot be interpreted economically. For this reason, in Figure 6 the AARs corresponding to the statistically significant SAARs have been shown. The sign of the AAR indicates whether the effect on the incumbents has been positive or negative.

There are multiple statistically significant SAARs during the event period. Tests A.P and B.P are more robust than test A and $\mathrm{B}$, because they do not reject the null-hypothesis due to the volatility induced by the event. This is consistent with the high number of statistically significant SAARs obtained in tests A.P and B.P, represented by their related AARs, compared with the statistically significant AARs obtained in test $\mathrm{A}$ and $\mathrm{B}$.

In Fig. (6), negative AARs, which correspond to statistically significant SAARs, surround the event.

The D.P and E.P tests were used to analyze the SCAARs. Both indicate statistically significant non-zero SCAARs with a level of confidence greater or equal to $95 \%$. Since the SCAARs have no economic interpretation, Figure 7 and Figure 8 represent that the CAARs correspond to the statistically significant SCAARs.

The D.P and E.P tests show their maximum and minimum in the same spots as the D and E tests do. The results of the panel, where the companies placed in the same subsector as the IPO were analyzed, are mainly negative. Therefore, a competitive effect seems to take place. 
When the volatility induced by the IPO is not considered, statistically significant CAARs appear along the whole study period. Therefore, the effect seems to be noticeable all the time.

The set of vectors, which starts at the beginning of the study period and ends at the 26th trading date after the event, show that the statistically significant negative effects progressively rise, following a saw-tooth pattern. After the 26th trading day they abruptly end. The peaks of the effect are related with the maximums and minimums of tests A.P and B.P.

An opposite effect can be seen during the last five days of the study period. It is positive and less intense. It progressively increases until the 27th trading day after the event. Then it decreases, at the same rate, until the 29th trading day after the event.

\section{DISCUSSION}

Under tests A, B, and C, statistically significant and mainly negative AARs arise. Those are prominent during the trading days around the event. The results of the $\mathrm{D}$ and $\mathrm{E}$ tests show a major negative effect. It reaches a minimum of $-2.91 \%$ under the vector $[-6,26]$. A positive and less intense effect appears at the end of the study period. It reaches a maximum of $1.01 \%$ under the vector [27, 29]. This opposite effect is shallower and narrower than the main one. To measure the length and depth of the statistically significant effects from a continuous perspective, the self-developed tool was used. Table 8 summarizes the effects. The main negative effect is highlighted in red, the small secondary positive one in blue.

Table 8. Effects Summary

\begin{tabular}{|c|c|c|c|c|c|c|c|c|c|c|c|c|c|}
\hline $\begin{array}{c}\text { Period days of the } \\
\text { Event }\end{array}$ & -30 & -25 & $\mid-20$ & -15 & -10 & -5 & $\mathbf{0}$ & 5 & 10 & 15 & 20 & 25 & 30 \\
\hline $\begin{array}{c}\text { Effects on companies } \\
\text { of a subsector }\end{array}$ & & & & & & - & - & - & - & - & - & - & \\
\hline Text in red & \multicolumn{13}{|c|}{ Main negative effect } \\
\hline Text in blue & \multicolumn{13}{|c|}{ Secondary small positive effect } \\
\hline
\end{tabular}

Source: Own elaboration

The self-developed tool depicts the saw-tooth waves represented in Figures 4, 5, 7, and 8, which show the shape of the effect. The maximums and minimums of Fig. (3) and (6) cause the tooth-wave shaped effect.

When an IPO takes place in a subsector, the returns of the firms in the same subsector react negatively. The effect found is around 3\%. It begins five trading days before the event and ends 25 trading days after. The direction of the effect is opposite to the original supply shock. Therefore, the competitive effect prevails. This result is aligned with those of previous major studies. The sudden end of the main effect gives way to an opposite one.

The covariances, in prices and returns, between the incumbents and the IPO are mainly positive. The asset pricing models which state that investors have a CRRA, as well as the behavioral finance ones, which consider that the investors show a CARA, forecast a drop in the stock prices of the related firms. This negative effect prediction agrees with the obtained results.

A theory to explain the competitive effect anomaly is proposed: A substitution relationship among the shares of rival companies exits. The theory arises when relating the found effect with the laws of supply and demand and with the substitutive and complementary goods theory. The covariances in prices and returns between the IPO and the incumbent firms are mainly positive. This denotes that there is a substitution relationship between them (they are competitors). When one's price is being modified - ceteris paribus - the price of the other one changes in the same direction. This is due to the movement of the demand curve in the same way as the prices did. Therefore, a positive supply shock will induce a decline in the prices of the publicly traded rivals. The opposite will be triggered by a negative supply shock. This explains the competitive effect anomaly that widespread in the literature.

\section{CONCLUSIONS}

A market anomaly was identified. The literature review, which analyzed the supply shock effects on publicly traded rivals, identified the prevalence of a reaction opposite in direction to the original supply shock. The different studies revealed that the outcome is constant across time and markets. Therefore, this study identified it as an anomaly. Following the previous literature, in this paper, the anomaly is called the competitive effect. The contagion effect was redefined as a reaction in the same direction as the initial supply shock.

To be able to visualize, from a continuous perspective, over all the subperiods in which the studied period can be divided, the effects induced by an event, a 3D graphic tool was developed. This tool highlights the information transmission process over the market. This process is the backbone of the semi-strong EMH (Fama, 1970, 1991) and the foundation of several asset pricing theories.

This study analyzed the short-term effect that an IPO has on publicly traded competitors on the Spanish stock market. A 30-year period was analyzed, from February 1986 until July 2016. The narrowness and shallowness of this market, given the lack of agreement on a classification of competitors, allowed us to identify as rivals all the firms that belong to the same subsector. The prevalence of positive covariance, in prices and returns, among the identified competitors confirm the competitive relationship.

The statistical and economic significance of the competitive effect anomaly was tested. A maximum value of approximately $3 \%$ was found. The result is statistically significant from five trading days before the IPO until 25 days afterwards. A 3\% mean return can be obtained by selling shares of the competitors just before the IPO and buying them afterwards. These results agree with the ones obtained by the major studies. The new tool allows the measurement of the extent and depth of the rivals' reactions. The 3D graphics show that the responses are not linear. Instead, they are produced in waves. These waves are aligned with the days of the maximum disturbances. The negative effects stop sud- 
denly at the end of the studied period. They give way to a less severe and opposite statistically significant disruption.

A theory capable of explaining the identified anomaly is proposed: There is a substitution relationship between the shares of the publicly traded rivals.

The projections of the main asset pricing models (CRRA and CARA) are the seed of the proposed theory. The major covariances, in prices and returns, between the IPO and the competitor firms are positive. Therefore, both types of models predict a substitution relationship among the rivals and the IPO (when the firms are market opponents). These projections agree with the previous literature and with the obtained competitive effect results. The analyses of the projection show a similarity between the identified anomaly (competitive effect) and the substitutive product theory (that comes from the supply and demand laws). The substitution relationship explains the direction of the competitive effect on a publicly traded rival that arises when a supply shock appears.

The main limitation of this study is its scope. It only synthesizes and analyzes the effects provoked by a supply shock on the rivals. The widening of the literature review and its study of the possible returns induced on the related companies could lead to a completion of the proposed theory.

Another of its limitations is that the methodology and the systematic analysis, from a continuous perspective used, focus only on a specific stock market. The broadening of the research to other financial and stock markets could help us to understand the identified anomaly even better.

Only a few previous studies used the main asset price projection models. Using these projections on the previous studies will allow a better understanding of the existing relationship between the competitive effect anomaly and the possible substitution effect among publicly traded rivals. These will help to verify the proposed theory. This line of research could be completed analyzing the effects induced by a demand shock and comparing them with the proposed theory.

Finally, the last line of research proposed is to use the developed tool in any event study. This will enlighten the extent, depth, and contiguity of the information spreading process and its effects on the prices and shares returns. This will help to define the time frame where several asset pricing models exist and at the same time it will improve the asset allocation decision making process.

\section{APPENDIX A.}

The results of test $\mathrm{E}$ on firms in the same subsector are shown. The statistically significant positive CAARs are in black, while the negative ones are in red. The blank spaces represent non-significant CAARs.

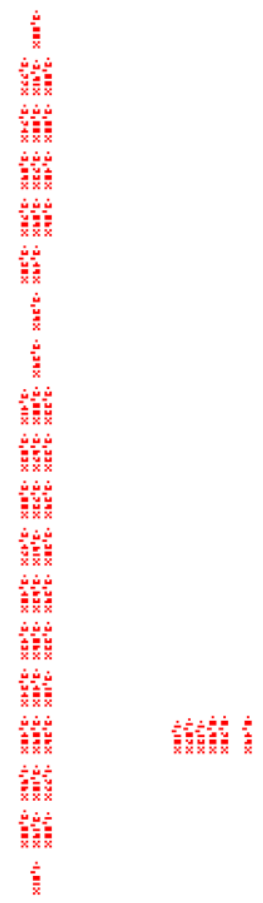

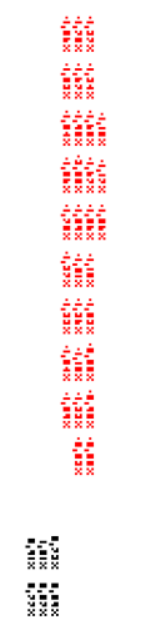

Fig. (9). Test E. Same Subsector Firms.

\section{APPENDIX B.}

The results of test E.P. on firms in the same subsector are shown. The positive statistically significant CAARs are in black, while the negative ones are in red. The blank spaces represent the non-significant CAARs. 


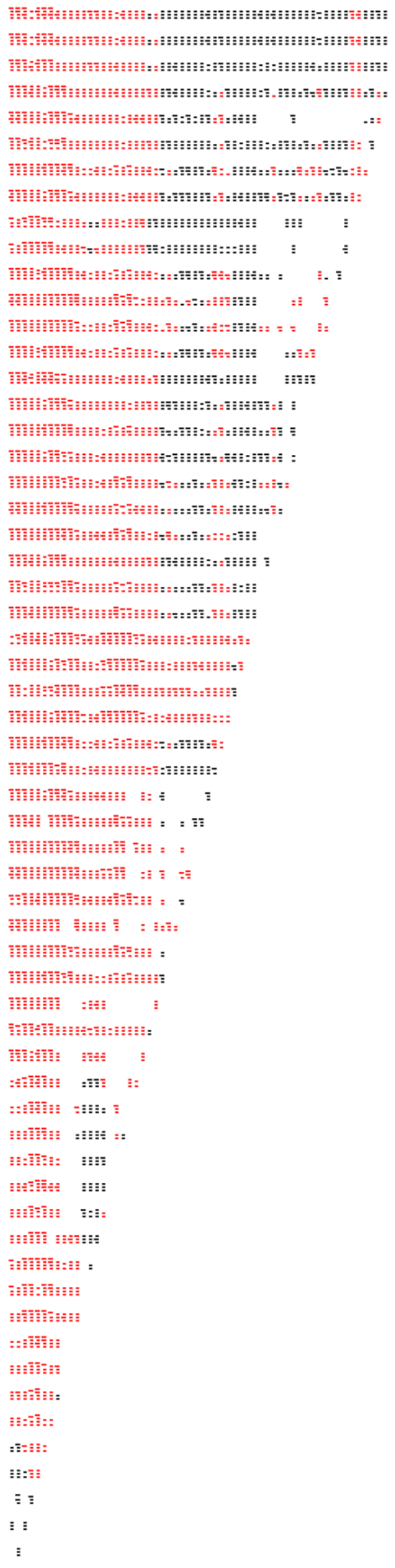

Fig. (10). Test E.P. Same Subsector Firms.

\section{LIST OF ABBREVIATIONS}

AAR: average abnormal returns

CAAR: cumulative average abnormal returns

CARA: constant absolute risk aversion

CRRA: constant relative risk aversion

EMH: Efficient Market Hypothesis

IPO: initial public offering

SAAR: standardized average abnormal returns

SCAAR: standardized cumulative average abnormal returns

\section{CONFLICT OF INTEREST}

Declarations of interest: none.

Funding: This research did not receive any specific grant from funding agencies in the public, commercial, or not-forprofit sectors.

\section{REFERENCES}

Akhigbe, A., Borde, S., Whyte, A., 2003. Does an industry effect exist for initial public offerings? Financ. Rev. 38, 531-551 https://doi.org/10.1111/1540-6288.00059

Brands, L., 2014. The stock effect of initial public offerings on industry rivals. Master's Thesis, Tilburg University. http://arno.uvt.nl/show.cgi?fid=135790 (accessed 10 November 2019).

Braun, M., Larrain, B., 2009. Do IPOs affect the prices of other stocks? Evidence from emerging markets. Rev. Financ. Stud. 22, 15051544. https://doi.org/10.1093/rfs/hhn025

Cheng, L.T.W., McDonald, J.E., 1996. industry structure and ripple effects of bankruptcy announcements. Financ. Rev. 31, 783-807. https://ideas.repec.org/a/bla/finrev/v31y1996i4p783-807.html (accessed 10 November 2019).

Chod, J., Lyandres, E., 2011. Strategic IPOs and product market competition. J. Financ. Econ. 100, 45-67. https://doi.org/10.1016/j.jfineco.2010.10.010

De Oliveira, G., 2015. Uma análise da Alibaba: impactos competitivos de seu IPO em seu mercado setorial. http://dspace.insper.edu.br/xmlui/handle/11224/1306 (accessed 10 November 2019).

Dore, T.E., 2015. Venture capital and the performance of incumbents. FEDS 2015, 1-44. https://doi.org/10.17016/FEDS.2015.080

Elyasiani, E., Kalotychou, E., Staikouras, S.K., Zhao, G., 2015. Return and volatility spillover among banks and insurers: Evidence from precrisis and crisis periods. J. Financ. Serv. Res. 48, 21-52. https://doi.org/10.1007/s10693-014-0200-z

Ergincan, Y., Kiraz, F., Uysal, Ö., 2016. Why go public? An empirical analysis of IPO's competitive effect on Turkish firms. Int. J. Comm. Finance. 2, 91-101. http://ijcf.ticaret.edu.tr/index.php/ijcf/article/view/17 (accessed 10 November 2019).

Fama, E.F., 1970. Efficient capital markets: A review of theory and empirical work. J. Finance. 25, 383. https://doi.org/10.2307/2325486

Fama, E.F., 1991. Efficient capital markets: II. J. Finance. 46, 1575-1617. https://doi.org/10.2307/2328565

Helwege, J., Zhang, G., 2016. Financial firm bankruptcy and contagion. Rev. Finance. 20, 1321-1362. https://doi.org/10.1093/rof/rfv045

Hertzel, M.G., Li, Z., Officer, M.S., Rodgers, K.J., 2008. Inter-firm linkages and the wealth effects of financial distress along the supply chain. J. Financ. Econ. 87, 374-387. https://doi.org/10.1016/j.jfineco.2007.01.005

Hsu, H.-C., Reed, A., Rocholl, J., 2010a. Competitive effects of private equity investments. SSRN Electronic Journal. https://doi.org/10.2139/ssrn.1571207 
Hsu, H.-C., Reed, A.V., Rocholl, J., 2010b. The new game in town: Competitive effects of IPOs. J. Finance. 65, 495-528. https://doi.org/10.1111/j.1540-6261.2009.01542.x

Kilander, C., Matsson, G., 2011. Competitive effects of initial public offerings in Sweden. Bachelor's Thesis in Finance.

http://arc.hhs.se/download.aspx?mediumid=1654 (accessed 10 November 2019).

Lang, L.H.P., Stulz, René M., 1992. Contagion and competitive intraindustry effects of bankruptcy announcements: An empirical analysis. J. Financ. Econ. 32, 45-60.https://doi.org/10.1016/0304405X(92)90024-R

Lo, A.W., 2004. The adaptive markets hypothesis: Market efficiency from an evolutionary perspective (SSRN Scholarly Paper No. ID 602222). Social Science Research Network, Rochester, NY. https://papers.ssrn.com/abstract=602222 (accessed 10 November 2019).

Markowitz, H.M., 1959. Portfolio selection: Efficient diversification of investments. Yale University Press. https://www.jstor.org/stable/j.ctt1bh4c8h (accessed 10 November 2019).

McGilvery, A., Faff, R., Pathan, S., 2012. Competitive valuation effects of Australian IPOs. Int. Rev. Financ. Anal. 24, 74-83. https://doi.org/10.1016/j.irfa.2012.08.002

Patell, J.M., 1976. Corporate forecasts of earnings per share and stock price behavior: Empirical Test. J. Account. Res. 14, 246-276. https://doi.org/10.2307/2490543

Patell, J.M., 1979. The API and the design of experiments. J. Account. Res. 17, 528-549. https://doi.org/10.2307/2490517

Slovin, M.B., Sushka, M.E., Bendeck, Y.M., 1991. The intra-industry effects of going-private transactions. J. Finance. 46, 1537-1550. https://doi.org/10.2307/2328871

Slovin, M.B., Sushka, M.E., Ferraro, S.R., 1995. A comparison of the information conveyed by equity carve-outs, spin-offs, and asset selloffs. J. Financ. Econ., Symposium on Corporate Focus 37, 89-104. https://doi.org/10.1016/0304-405X(94)00796-4

Copyright @ 2020- All Rights Reserved

This is an open-access article. 